\title{
Safety of lorlatinib following alectinib-induced pneumonitis in two patients with $A L K$-rearranged non-small cell lung cancer: a case series
}

\author{
Nathaniel J. Myall ${ }^{1}$, Amy Q. Lei ${ }^{2}$, Heather A. Wakelee ${ }^{1}$ \\ ${ }^{1}$ Division of Oncology, Stanford Cancer Institute, Stanford, CA, USA; ${ }^{2}$ Division of Oncology, Kaiser Permanente Santa Clara Medical Center, Santa \\ Clara, CA, USA \\ Correspondence to: Dr. Heather A. Wakelee, MD. Stanford Cancer Institute, 875 Blake Wilbur Drive, Stanford, CA 94305, USA. \\ Email: hwakelee@stanford.edu.
}

\begin{abstract}
Drug-induced interstitial lung disease (DI-ILD) is a rare adverse event associated with targeted therapies that inhibit the anaplastic lymphoma kinase (ALK) protein. Although newer-generation ALK inhibitors such as alectinib significantly improve survival in metastatic $A L K$-rearranged non-small cell lung cancer (NSCLC), the risk of DI-ILD is similar to that of earlier-generation therapies. Lorlatinib is a thirdgeneration ALK inhibitor that is active in patients with metastatic NSCLC whose tumors have developed secondary resistance to alectinib. While it is associated with low rates of DI-ILD in initial phase $1 / 2$ clinical trials, the safety of lorlatinib in patients with a history of DI-ILD has not been well-described. In this case series, we therefore report two patients with metastatic $A L K$-rearranged NSCLC who each tolerated lorlatinib following recovery from alectinib-related DI-ILD. Both cases were notable for the acute onset of dyspnea, hypoxia, and diffuse ground-glass opacities within one month of initiating alectinib. With no alternative etiology of pneumonitis identified, both patients were treated empirically for grade 3 DIILD with corticosteroids and discontinuation of alectinib. Following rapid clinical recovery and eventual radiographic resolution of opacities, each patient was started on lorlatinib at the time of cancer progression, with neither person developing symptoms or radiographic findings consistent with recurrent DI-ILD. In the following series, we describe these two cases in greater detail and discuss their significance within the context of the prior literature. While further descriptions are needed, our experience suggests that lorlatinib may be a safe therapeutic option in some patients who have recovered from DI-ILD.
\end{abstract}

Keywords: Non-small cell lung cancer (NSCLC); anaplastic lymphoma kinase (ALK); interstitial lung disease; alectinib; lorlatinib; case series

Submitted Apr 19, 2020. Accepted for publication Aug 28, 2020.

doi: $10.21037 /$ tlcr-20-564

View this article at: http://dx.doi.org/10.21037/tlcr-20-564

\section{Introduction}

Alectinib is a second-generation tyrosine kinase inhibitor (TKI) that significantly improves progression-free survival compared to crizotinib in untreated patients with metastatic, anaplastic lymphoma kinase (ALK)-rearranged non-small cell lung cancer (NSCLC) (1). Like other ALK inhibitors, it is associated in rare cases with serious adverse events such as drug-induced interstitial lung disease (DI-ILD) or pneumonitis. Because DI-ILD is thought to represent a potential side-effect of all ALK inhibitors, switching from alectinib to another targeted therapy within the same class requires careful consideration in those patients who have a history of DI-ILD.

Lorlatinib is a novel, third-generation ALK inhibitor that has activity against acquired $A L K$ resistance mutations (e.g., G1202R) and has been associated with low rates $(<1 \%)$ of DI-ILD in phase $1 / 2$ clinical trials (2-4). These previous studies, however, specifically excluded patients who had a 


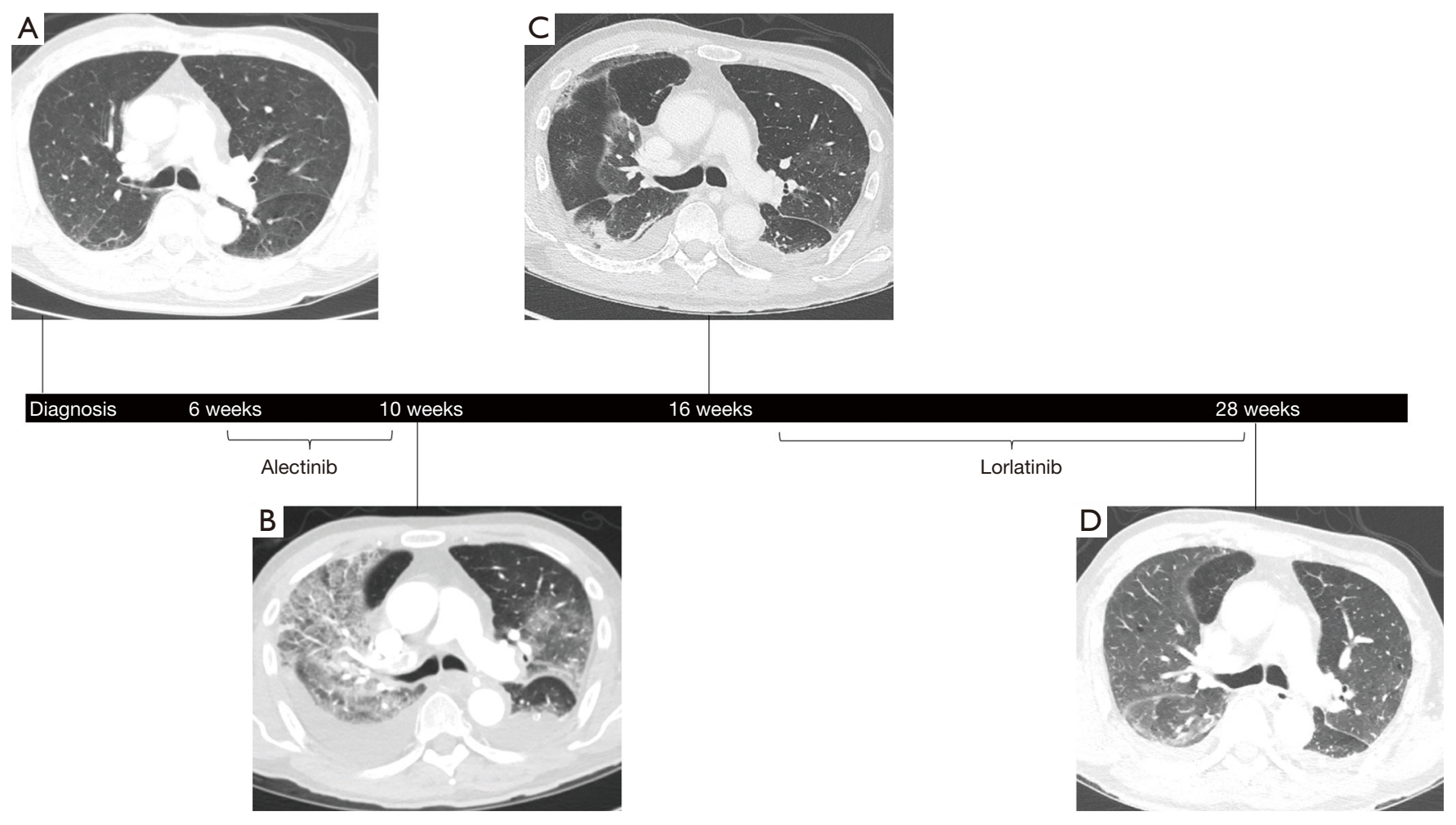

Figure 1 Serial CT images of the chest were collected in the first patient from the time of diagnosis through follow-up on lorlatinib. At the time of presentation with NSCLC, no parenchymal abnormalities were observed aside from the primary tumor (not shown) (A). However, bilateral, diffuse ground-glass opacities and septal thickening became apparent 29 days after the initiation of alectinib when the patient developed worsening respiratory symptoms and hypoxia (B). Approximately 5 weeks after initiating corticosteroids and discontinuing alectinib for grade 3 DI-ILD, the previously seen parenchymal abnormalities were significantly improved (C). After 10 weeks on lorlatinb therapy, despite progression of NSCLC (not shown), only faint ground-glass opacities were visible compared to prior (D). NSCLC, nonsmall cell lung cancer; DI-ILD, drug-induced interstitial lung disease.

history of grade 3-4 interstitial lung disease, and thus, both the optimal treatment of such patients and the full safety profile of lorlatinib with respect DI-ILD remain unclear. To begin addressing some of these unanswered questions, we describe two patients with $A L K$-rearranged NSCLC who each safely tolerated lorlatinib without recrudescent symptoms following recovery from grade 3 DI-ILD secondary to alectinib. We present the article in accordance with the CARE reporting checklist (available at http:// dx.doi.org/10.21037/tlcr-20-564) (5).

\section{Case presentation}

\section{Case \#1}

An 80-year-old Asian, non-smoking man with a history of stroke presented in 2018 with chest pain, fatigue, and weight loss. A CT scan revealed a cavitary mass in the left lower lung measuring $6.5 \mathrm{~cm} \times 4.3 \mathrm{~cm} \times 3.3 \mathrm{~cm}$ without diffuse parenchymal disease (Figure 1A). PET-CT demonstrated additional hypermetabolic activity in the left hilar (SUV 6.8) and para-esophageal lymph nodes (SUV 4.4), bilateral adrenal glands (SUV 6.9), and right kidney (SUV 13.6). MRI of the brain revealed a punctate enhancing lesion in the right cerebellum, concerning for metastasis. Biopsy of the cavitary lung mass was consistent with a CK7+, TTF1+, CK20- lung adenocarcinoma with high PD-L1 expression (70\%). Fluorescence in-situ hybridization (FISH) further revealed the presence of an $A L K$ rearrangement.

Several weeks following the diagnosis of stage IV (cT3N2M1c) $A L K$-rearranged NSCLC, the patient was started on first-line alectinib $600 \mathrm{mg}$ twice daily. On day 18 of therapy, he was admitted to the hospital with dyspnea and chest pain secondary to both multifocal pulmonary 
emboli and a large left pleural effusion. Despite appropriate treatment with therapeutic anticoagulation, placement of an indwelling pleural catheter, and continuation of alectinib, the patient developed worsening hypoxia on hospital day 11 , requiring $8 \mathrm{~L} / \mathrm{min}$ of oxygen by highflow nasal cannula. A repeat CT scan of the chest at this time showed regression of the known pulmonary emboli and pleural effusion but interval development of diffuse ground-glass opacities and septal thickening (Figure 1B). Although sputum was positive for Enterobacter cloacae, the patient had no fever or leukocytosis and did not improve with piperacillin-tazobactam. Pulmonary edema was similarly considered to be unlikely given negative troponin levels $(<0.055)$ and a recent echocardiogram showing normal left ventricular function without valvular abnormalities. Because the patient's precarious respiratory status prohibited bronchoscopy, methylprednisolone $60 \mathrm{mg}$ intravenously (IV) daily was started empirically for grade 3 pneumonitis. By 48 hours later, his clinical status had improved significantly, with supplemental oxygen weaned to $4 \mathrm{~L} / \mathrm{min}$. Alectinib was discontinued at this time, and the patient continued to remain stable with decreasing oxygen requirements while he awaited eventual discharge to a skilled nursing facility.

Approximately four weeks after hospitalization, while remaining on a slow steroid taper, a repeat CT scan of the chest, abdomen, and pelvis showed resolving ground-glass opacities (Figure 1C). However, there was also evidence of tumor growth, and therefore, following a careful discussion of the potential risks and alternatives, he started second-line lorlatinib $100 \mathrm{mg}$ daily a few weeks later. After 10 weeks on lorlatinib, repeat CT scan of the chest, abdomen, and pelvis showed only faint residual ground-glass opacities, and the patient was asymptomatic without hypoxia despite having been weaned to prednisone $2 \mathrm{mg}$ daily, indicating no recurrence of pneumonitis (Figure 1D). Unfortunately, the CT scan also revealed progression in both the lung and left adrenal gland, and a MRI of the brain showed new lesions in the left temporal horn and left frontal lobe. Lorlatinib was discontinued due to lack of efficacy, and the patient was transitioned to hospice care. He passed away shortly thereafter, with overall survival (OS) lasting approximately 7 months from the time of diagnosis.

\section{Case \#2}

A 66 years old Caucasian, never-smoking woman with a history of depression presented in 2018 with several weeks of intermittent pain in the right upper back. A CT scan of the chest, abdomen, and pelvis showed a $2.9 \mathrm{~cm} \times$ $2.6 \mathrm{~cm}$ spiculated lesion in the right inferior hilar region of the lung without diffuse parenchymal disease (Figure $2 A$ ). Additional findings included subcarinal and hilar lymphadenopathy, multiple liver lesions measuring up to $2.5 \mathrm{~cm}$, and a nodular density near the left adrenal gland. Biopsy of a single liver lesion revealed a CK7+, TTF1+ lung adenocarcinoma with high PD-L1 expression $(>50 \%)$. As a result of the patient's symptom burden and the inadequate tissue available for next-generation sequencing (NGS), she was started on pembrolizumab $200 \mathrm{mg}$ IV every 3 weeks for stage IV (cT1cN2M1c) NSCLC. After two cycles of immunotherapy, her disease was found to have progressed, and therefore, she was switched to second-line alectinib $600 \mathrm{mg}$ twice daily based on repeat molecular sequencing that revealed an EML4-ALK rearrangement.

On day 26 of alectinib, the patient presented to the hospital with acute dyspnea and hypoxia requiring $100 \%$ FiO2 by face mask. A CT scan of the chest showed new diffuse, bilateral ground-glass opacities along with moderate, bilateral pleural effusions (Figure 2B). A basic infectious work-up, consisting of blood and sputum cultures, was unrevealing. The patient was offered bronchoscopy for further diagnostic evaluation but declined. Therefore, given clinical suspicion for grade 3 pneumonitis secondary to alectinib, her cancer therapy was empirically discontinued, and she was started on methylprednisolone $40 \mathrm{mg}$ IV every 8 hours in addition to broad-spectrum antibiotics. Within 48 hours, the patient's condition rapidly improved, and by hospital day 5 , she was weaned off all supplemental oxygen and safely discharged from the hospital.

Three weeks following hospitalization, while remaining on a slow steroid taper, a repeat CT scan of the chest showed complete radiographic resolution of groundglass opacities (Figure 2C). The patient therefore began third-line carboplatin, area under the curve (AUC) (5), plus pemetrexed $500 \mathrm{mg} / \mathrm{m}^{2}$ but she developed further tumor progression after two cycles. Following a detailed discussion of the risks and benefits, she was switched to fourth-line lorlatinib $75 \mathrm{mg}$ daily while also remaining on dexamethasone $1 \mathrm{mg}$ twice daily for chronic back pain. An interval PET-CT scan subsequently demonstrated a near complete response with resolution of lesions in the right middle lung and liver. The patient has thus far remained on lorlatinib for $>10$ months without clinical or radiographic evidence of recurrent DI-ILD (Figure 2D).

Both patients provided informed consent for the 


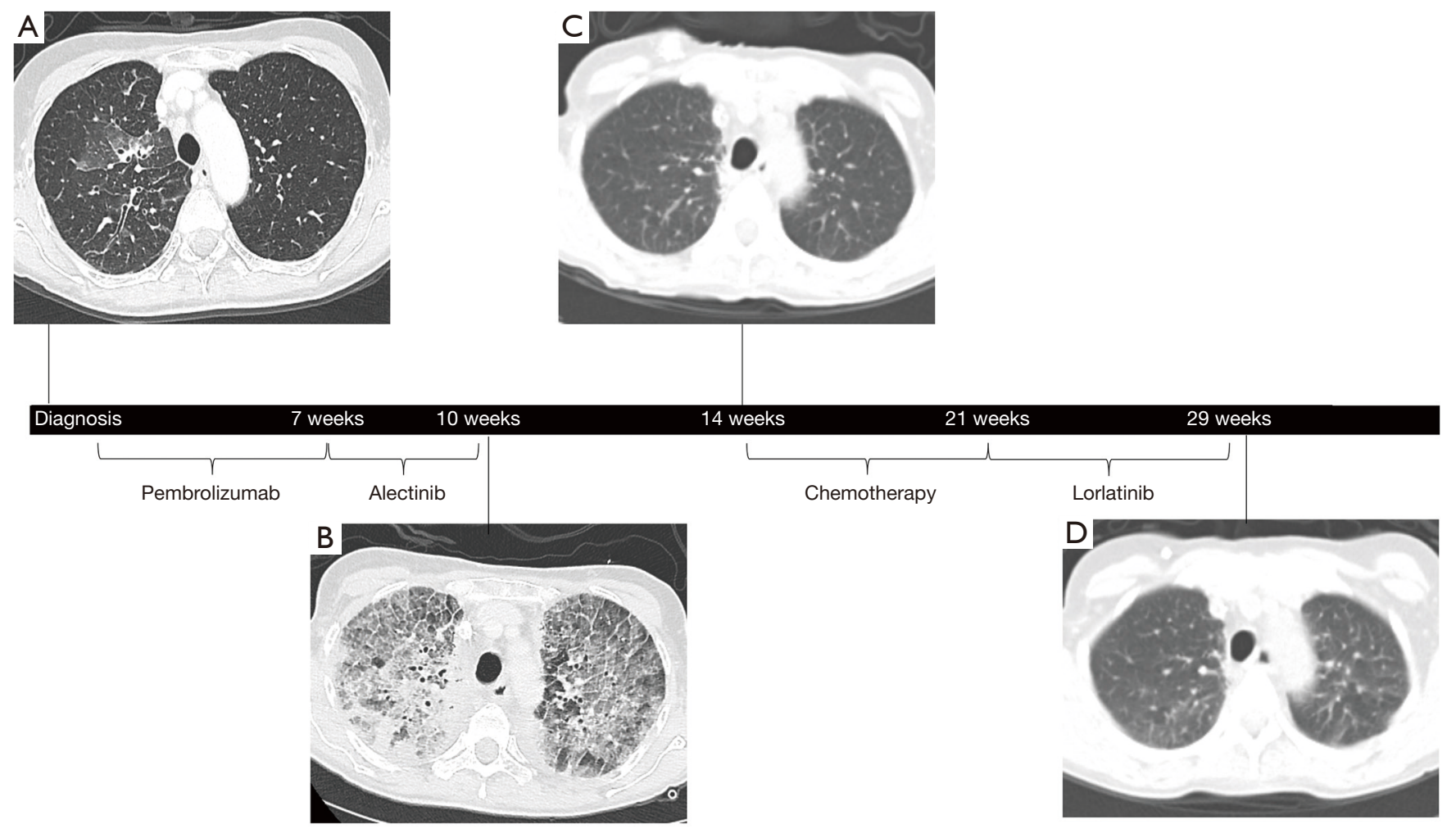

Figure 2 Serial CT images of the chest were collected in the second patient from the time of diagnosis through follow-up on lorlatinib. At the time of diagnosis with NSCLC, no parenchymal abnormalities were observed aside from the primary tumor (not shown) (A). When the patient was hospitalized with hypoxia and respiratory symptoms on day 26 of alectinib, diffuse ground-glass opacities involving the entirety of both lung fields were now noted (B). Approximately 3 weeks after discharge from the hospital, while the patient remained on corticosteroids and off alectinib, the previously seen parenchymal abnormalities were resolved (C). Despite later switching to lorlatinib, the lungs remained clear without recurrent ground-glass opacities (D).

reporting of their relevant medical histories in this manuscript. All procedures performed in studies involving human participants were in accordance with the ethical standards of the institutional and/or national research committee(s) and with the Helsinki Declaration (as revised in 2013).

\section{Discussion}

To our knowledge, the safety of lorlatinib in patients with a history of DI-ILD has not been previously reported. Although the incidence of DI-ILD secondary to ALK targeted therapy is low, it carries a $50 \%$ risk of mortality according to one prior case series (6). The occurrence of this serious adverse event also has the potential to impact long-term cancer control by limiting further use of highly effective ALK inhibitors. For these reasons, it is important not only to understand the management of DI-ILD in the acute setting but also to recognize what constitutes safe, effective anti-cancer therapy following recovery from DIILD.

Drug-induced ILD is characterized by progressive respiratory symptoms and radiographic pulmonary abnormalities following exposure to a culprit medication (7). In the case of ALK inhibitors, in particular, DI-ILD has been reported in small numbers of patients across multiple prospective trials (8-11). A pooled analysis of four studies investigating crizotinib (PROFILE 1001/1005/1007/1014), for example, reported de novo DI-ILD in $1.2 \%$ of patients (6). Like cases of DI-ILD occurring secondary to other medications, common symptoms include fever, dyspnea, and cough, often beginning within 1-2 months of drug initiation (6). Although alectinib has now replaced crizotinib as first-line therapy in patients with 
metastatic, $A L K$-rearranged NSCLC, its risk of causing DI-ILD appears to be similar. In the J-ALEX trial, for example, DI-ILD occurred in $8 \%$ of Japanese patients in both the alectinib and crizotinib arms (12). While drug discontinuation secondary to DI-ILD was less common with alectinib than crizotinib $(0.7 \%$ vs. $3.3 \%)$ in the international ALEX trial, the small number of patients developing DI-ILD in either arm limited statistical comparison (1). Conversely, a meta-analysis of 18 studies found that the lower incidence of all-grade DI-ILD in patients receiving alectinib versus crizotinib (1.62\% vs. $2.68 \%$ ) did not reach statistical significance $(\mathrm{P}=0.092)(13)$.

As a clinical entity, DI-ILD encompasses a number of distinct histologic patterns in the lung including diffuse alveolar damage, organizing pneumonia, and eosinophilic pneumonia, among others $(7,14)$. Diffuse alveolar damage, in particular, is defined pathologically by hyaline membrane formation and exudative edema, and it often manifests clinically with hypoxia and bilateral ground-glass opacities suggestive of adult respiratory distress syndrome (ARDS) $(14,15)$. In the case of DI-ILD secondary to ALK inhibitors, it has been suggested that diffuse alveolar damage correlates with an acute and severely symptomatic form of the disease in which patients are at risk for decompensation and death without discontinuation of ALK targeted therapy (16). On the other hand, a delayed form of DI-ILD occurring several months after the start of ALK targeted therapy is characterized by fewer symptoms and focal, less prominent ground-glass opacities (16). Although pathologic data was not obtained in our two patients, their clinical presentation was similar to that of prior cases of DI-ILD that have been associated with diffuse alveolar damage on post-mortem evaluation $(17,18)$.

Because of the mortality associated with DI-ILD, the question of whether or not to restart ALK targeted therapy in patients who have a history of DI-ILD requires careful consideration. A limited number of previous case reports have described the successful use of crizotinib, ceritinib, alectinib, or brigatinib in patients with $A L K$-rearranged NSCLC who have recovered from DI-ILD secondary to ALK targeted therapy (Table 1) (19-31). In some of these cases, however, patients resumed ALK targeted therapy after having mild and/or delayed presentations of DI-ILD marked by focal opacities $(19,20,26,28)$. As discussed above, this may represent a distinct form of DI-ILD for which continuation of ALK inhibitor therapy is not prohibited (16). In comparison, both patients in our series presented with acute, severe DI-ILD, and thus, their subsequent tolerance of lorlatinib was notable. While it is unclear to what extent the ongoing use of steroids played a protective role in our patients, the doses being used at the time of starting lorlatinib were much lower than the treatment doses typically indicated for active DI-ILD.

Although DI-ILD is uncommon, potential risk factors for the disease have been previously identified in patients receiving ALK targeted therapy. These include older age, Japanese ethnicity, positive smoking history, and the presence of concurrent pleural effusions $(6,32)$. A more recently identified risk factor that may have played a role in the development of DI-ILD in our second patient, in particular, is the use of immune checkpoint inhibitor therapy prior to TKI therapy. In multiple series of patients with epidermal growth factor receptor (EGFR)-mutated NSCLC, for example, the incidence of pneumonitis has been found to be higher in those patients who have received PD-1/PD-L1 inhibitors prior to EGFR targeted therapy $(33,34)$. A similar phenomenon has been demonstrated in patients with $A L K$-rearranged NSCLC in whom the incidence of grade 3-4 transaminitis has been shown to be significantly higher in patients receiving checkpoint inhibitors prior to crizotinib [45.5\% versus $8.1 \%$ for elevated alanine transaminase (ALT) and $36.4 \%$ versus $3.4 \%$ for elevated aspartate transaminase (AST)] (35).

Together, these results suggest that the sequential use of checkpoint inhibitors before TKI therapy may exacerbate the risk of immune-related and/or TKI-related adverse events such as DI-ILD. For those patients with severely symptomatic disease at the time of diagnosis, starting therapy immediately may be necessary prior to knowing the results of EGFR and/or $A L K$ molecular testing. However, this is challenging in patients who ultimately have $A L K$ rearranged NSCLC given that $A L K$ rearrangements have been associated with PD-L1 expression but are not predictive of response to immunotherapy $(36,37)$. Therefore, given both the lack of efficacy and the increased risk of side-effects, checkpoint inhibitors should be deferred while awaiting molecular results in patients who, by virtue of their age or non-smoking status, have a high pretest probability of testing positive for a targetable driver mutation. Furthermore, studies suggest that patients are at greatest risk for adverse events when TKI therapy is initiated within 3 months of discontinuing checkpoint inhibition (34). However, pharmacodynamic studies also suggest that immune checkpoint inhibitors may have a continued effect on T-cells long after administration (38). 
Table 1 Prior case reports describing ALK inhibitor use after drug-induced pneumonitis

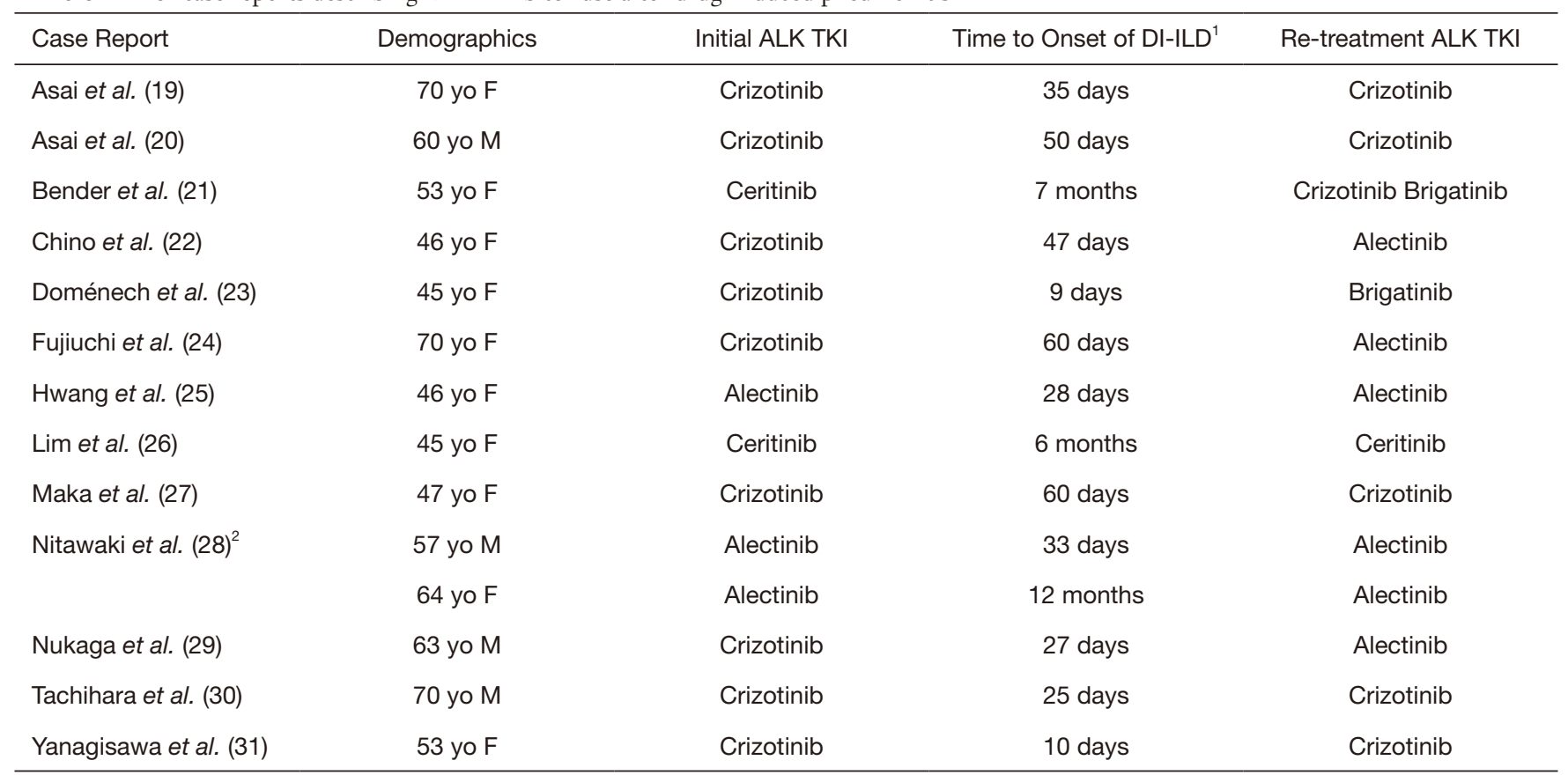

${ }^{1}$ Time of onset is defined is the duration in days or months from initiation of ALK targeted therapy to presentation with DI-ILD, ${ }^{2}$ Two cases described in the same case series. ALK, anaplastic lymphoma kinase; TKI, tyrosine kinase inhibitor; DI-ILD, drug-induced interstitial lung disease.

Therefore, it was notable that the second patient in this series tolerated lorlatinib despite both her history of severe DI-ILD and her recent exposure to immunotherapy just a few months prior.

Drug-induced ILD often remains a diagnosis of exclusion, although pathologic evaluation can provide supporting data $(7,14,15)$. Bronchoscopic evaluation or biopsy was prohibited in both patients in this series, either by patient choice or clinical instability. Nonetheless, the acute onset of radiographic abnormalities and rapid clinical recovery with steroids and discontinuation of alectinib strengthened the diagnosis of DI-ILD in both cases and encourages the reporting of larger patient cohorts in the future to confirm the hypotheses developed here. Another potential limitation of this case series is the lack of longterm follow-up data for the first patient who showed evidence of progression of NSCLC on first surveillance imaging after starting lorlatinib. While many severe cases of DI-ILD occur acutely, reports of long-term safety data will be important in the future to assess the potential for delayed adverse events secondary to lorlatinib.

In summary, we present two patients who tolerated lorlatinib without recurrent symptoms after developing severe, acute DI-ILD on alectinib. Although confirmation is warranted in additional patients, these results offer initial safety data suggesting that lorlatinib may be a reasonable alternative therapy to consider in patients who have recovered from DI-ILD. Given the efficacy of ALK inhibitors in patients with $A L K$-rearranged NSCLC, this offers hope that patients may continue to tolerate and benefit from ALK inhibitor therapy even after the development of significant grade $\geq 3$ DI-ILD.

\section{Acknowledgments}

The authors would like to thank the patients who are described in this manuscript. We would also like to thank the medical staff members who have provided care for the patients both in the hospital and the outpatient setting.

Funding: None.

\section{Footnote}

Reporting Checklist: The authors have completed the CARE reporting checklist. Available at http://dx.doi.org/10.21037/ tlcr-20-564 
Peer Review File: Available at http://dx.doi.org/10.21037/ tlcr-20-564

Conflicts of Interest: All authors have completed the ICMJE uniform disclosure form (available at http://dx.doi. org/10.21037/tlcr-20-564). Dr. Wakelee serves as an unpaid editorial board member of Translational Lung Cancer Research. Dr. Wakelee reports grants from Gilead; personal fees and non-financial support from AztraZeneca; personal fees and other from Xcovery, personal fees from Janssen, Daiichi Sankyo, INC, Helsinn, and Mirati; non-financial support from Takeda, and CellWorks; non-financial support and other from Genentech/Roche, Merck; non-financial support from Clinical Care Options Oncology, LLC, Fishawack Facilitate LTD, Medscape, Onclive/Intellisphere LLC, Phillips Gilmore Oncology (2018), Physicians Education Resource LLC/MJH (Targeted Oncology), Potomac Center for Medical Education (Rockpointe), Prime Oncology LLC (2018), Primo (2018), Research to Practice; personal fees from UpToDate; non-financial support from WebMD Health, Novartis, RGCON - Rajiv Gandi Conference, JLCS - Japanese Lung Cancer Society, KSMO - Korean Society of Medical Oncology, Stanford University, ITMIG, other from ACEA Biosciences; other from Arrys Therapeutics, AztraZeneca/MedImmune, BMS, Celgene, Clovis Oncology, Exelixis, Lilly, Pfizer, Pharmacyclics; which are all outside the submitted work. The other authors have no conflicts of interest to declare.

Ethical Statement: The authors are accountable for all aspects of the work in ensuring that questions related to the accuracy or integrity of any part of the work are appropriately investigated and resolved. Both patients provided informed consent for the reporting of their relevant medical histories in this manuscript. All procedures performed in studies involving human participants were in accordance with the ethical standards of the institutional and/or national research committee(s) and with the Helsinki Declaration (as revised in 2013).

Open Access Statement: This is an Open Access article distributed in accordance with the Creative Commons Attribution-NonCommercial-NoDerivs 4.0 International License (CC BY-NC-ND 4.0), which permits the noncommercial replication and distribution of the article with the strict proviso that no changes or edits are made and the original work is properly cited (including links to both the formal publication through the relevant DOI and the license). See: https://creativecommons.org/licenses/by-nc$\mathrm{nd} / 4.0 /$.

\section{References}

1. Camidge DR, Dziadziuszko R, Peters S, et al. Updated Efficacy and Safety Data and Impact of the EML4-ALK Fusion Variant on the Efficacy of Alectinib in Untreated ALK-Positive Advanced Non-Small Cell Lung Cancer in the Global Phase III ALEX Study. J Thorac Oncol 2019;14:1233-43.

2. Shaw AT, Felip E, Bauer TM, et al. Lorlatinib in nonsmall-cell lung cancer with ALK or ROS1 rearrangement: an international, multicentre, open-label, single-arm firstin-man phase 1 trial. Lancet Oncol 2017;18:1590-9.

3. Solomon BJ, Besse B, Bauer TM, et al. Lorlatinib in patients with ALK-positive non-small-cell lung cancer: results from a global phase 2 study. Lancet Oncol 2018;19:1654-67.

4. Shaw AT, Solomon BJ, Besse B, et al. ALK Resistance Mutations and Efficacy of Lorlatinib in Advanced Anaplastic Lymphoma Kinase-Positive Non-Small-Cell Lung Cancer. J Clin Oncol 2019;37:1370-9.

5. Gagnier JJ, Kienle G, Altman DG, et al. The CARE guidelines: consensus-based clinical case reporting guideline development. J Med Case Rep 2013;7:223.

6. Yoneda KY, Scranton JR, Cadogan MA, et al. Interstitial Lung Disease Associated With Crizotinib in Patients With Advanced Non-Small Cell Lung Cancer: Independent Review of Four PROFILE Trials. Clin Lung Cancer 2017;18:472-9.

7. Camus P, Fanton A, Bonniaud P, et al. Interstitial lung disease induced by drugs and radiation. Respiration 2004;71:301-26.

8. Peters S, Camidge DR, Shaw AT, et al. Alectinib versus Crizotinib in Untreated ALK-Positive Non-Small-Cell Lung Cancer. N Engl J Med 2017;377:829-38.

9. Camidge DR, Kim HR, Ahn MJ, et al. Brigatinib versus Crizotinib in ALK-Positive Non-Small-Cell Lung Cancer. N Engl J Med 2018;379:2027-39.

10. Soria JC, Yan DSW, Chiari R, et al. First-line ceritinib versus platinum-based chemotherapy in advanced ALKrearranged non-small-cell lung cancer (ASCEND-4): a randomised, open-label, phase 3 study. Lancet 2017;389:917-29.

11. Solomon BJ, Mok T, Kim DW, et al. First-line crizotinib versus chemotherapy in ALK-positive lung cancer. $\mathrm{N}$ Engl J Med 2014;371:2167-77. 
12. Hida T, Nokihara H, Kondo M, et al. Alectinib versus crizotinib in patients with ALK-positive non-small-cell lung cancer (J-ALEX): an open-label, randomised phase 3 trial. Lancet 2017;390:29-39.

13. Suh CH, Kim KW, Pyo J, et al. The incidence of ALK inhibitor-related pneumonitis in advanced non-smallcell lung cancer patients: A systematic review and metaanalysis. Lung Cancer 2019;132:79-86.

14. Müller NL, White DA, Jiang H, et al. Diagnosis and management of drug-associated interstitial lung disease. $\mathrm{Br}$ J Cancer 2004;91:S24-S30.

15. Min JH, Lee HY, Lim H, et al. Drug-induced interstitial lung disease in tyrosine kinase inhibitor therapy for nonsmall cell lung cancer: a review on current insight. Cancer Chemother Pharmacol 2011;68:1099-109.

16. Créquit P, Wislez M, Feith JF, et al. Crizotinib Associated with Ground-Glass Opacity Predominant Pattern Interstitial Lung Disease: A Retrospective Observational Cohort Study with a Systematic Literature Review. J Thorac Oncol 2015;10:1148-55.

17. Ono A, Takahashi T, Oishi T, et al. Acute lung injury with alveolar hemorrhage as adverse drug reaction related to crizotinib. J Clin Oncol 2013;31:e417-9.

18. Tamiya A, Okamoto I, Miyazaki M, et al. Severe acute interstitial lung disease after crizotinib therapy in a patient with EML4-ALK-positive non-small-cell lung cancer. J Clin Oncol 2013;31:e15-7.

19. Asai N, Yamaguchi E, Kubo A. Successful crizotinib rechallenge after crizotinib-induced interstitial lung disease in patients with advanced non-small-cell lung cancer. Clin Lung Cancer 2014; 15:e33-5.

20. Asai N, Yokoi T, Yamaguchi E, et al. Successful crizotinib rechallenge after crizotinib-induced organizing pneumonia in anaplastic lymphoma kinase-rearranged non-small cell lung cancer. Case Rep Oncol 2014;7:681-4.

21. Bender L, Meyer G, Quoix E, et al. Ceritinib-related interstitial lung disease improving after treatment cessation without recurrence under either crizotinib or brigatinib: a case report. Ann Transl Med 2019;7:106.

22. Chino H, Sekine A, Kitamura H, et al. Successful treatment with alectinib after crizotinib-induced interstitial lung disease. Lung Cancer 2015;90:610-3.

23. Doménech M, Jové $M$, Aso S, et al. Successful treatment with brigatinib in a patient with ALK-rearranged lung adenocarcinoma who developed crizotinib-induced interstitial lung disease. Lung Cancer 2018;119:99-102.

24. Fujiuchi S, Fujita Y, Ssaki T, et al. Successful alectinib treatment after crizotinib-induced interstitial lung disease.
Respirol Case Rep 2016;4:e00156.

25. Hwang A, Iskandar A, Dasanu C. Successful reintroduction of alectinib after inducing interstitial lung disease in a patient with lung cancer. J Oncol Pharm Pract 2019;25:1531-3.

26. Lim SM, An HJ, Park HS, et al. Organizing pneumonia resembling disease progression in a non-small-cell lung cancer patient receiving ceritinib: A case report. Medicine (Baltimore) 2018;97:e11646.

27. Maka VV, Krishnaswamy UM, Kumar AN, et al. Acute interstitial lung disease in a patient with anaplastic lymphoma kinase-positive non-small-cell lung cancer after crizotinib therapy. Oxf Med Case Reports 2014;2014:11-2.

28. Nitawaki T, Sakata Y, Kawamura K, et al. Case report: continued treatment with alectinib is possible for patients with lung adenocarcinoma with drug-induced interstitial lung disease. BMC Pulm Med 2017;17:173.

29. Nukaga S, Naoki K, Kamo T, et al. Alectinib as a treatment option following recovery from crizotinibinduced interstitial lung disease in patients with anaplastic lymphoma kinase-positive advanced non-small-cell lung cancer. Mol Clin Oncol 2016;4:1085-7.

30. Tachihara M, Kobayashi K, Ishikawa Y, et al. Successful crizotinib rechallenge after crizotinib-induced interstitial lung disease. Jpn J Clin Oncol 2014;44:762-4.

31. Yanagisawa S, Inoue A, Koarai A, et al. Successful crizotinib retreatment after crizotinib-induced interstitial lung disease. J Thorac Oncol 2013;8:e73-4.

32. Gemma A, Kusumoto M, Kurihara Y, et al. Interstitial Lung Disease Onset and Its Risk Factors in Japanese Patients With ALK-Positive NSCLC After Treatment With Crizotinib. J Thorac Oncol 2019;14:672-82.

33. Oshima Y, Tanimoto T, Yuji K, et al. EGFR-TKIAssociated Interstitial Pneumonitis in Nivolumab-Treated Patients With Non-Small Cell Lung Cancer. JAMA Oncol 2018;4:1112-5.

34. Schoenfeld AJ, Arbour KC, Rizvi H, et al. Severe immune-related adverse events are common with sequential PD-(L)1 blockade and osimertinib. Ann Oncol 2019;30:839-44.

35. Lin JJ, Chin E, Yeap BY, et al. Increased Hepatotoxicity Associated with Sequential Immune Checkpoint Inhibitor and Crizotinib Therapy in Patients with Non-Small Cell Lung Cancer. J Thorac Oncol 2019;14:135-40.

36. Ota K, Azuma K, Kawahara A, et al. Induction of PDL1 Expression by the EML4-ALK Oncoprotein and Downstream Signaling Pathways in Non-Small Cell Lung Cancer. Clin Cancer Res 2015;21:4014-21. 
37. Gainor JF, Shaw AT, Sequist LV, et al. EGFR Mutations and ALK Rearrangements Are Associated with Low Response Rates to PD-1 Pathway Blockade in Non-Small Cell Lung Cancer: A Retrospective Analysis. Clin Cancer Res 2016;22:4585-93.

Cite this article as: Myall NJ, Lei AQ, Wakelee HA. Safety of lorlatinib following alectinib-induced pneumonitis in two patients with $A L K$-rearranged non-small cell lung cancer: a case series. Transl Lung Cancer Res 2021;10(1):487-495. doi: 10.21037/tlcr-20-564
38. Brahmer JR, Drake CG, Wollner I, et al. Phase I study of single-agent anti-programmed death-1 (MDX1106) in refractory solid tumors: safety, clinical, activity, pharmacodynamics, and immunologic correlates. J Clin Oncol 2010;28:3167-75. 